\title{
A atuação do psicólogo escolar no ensino superior: configurações, desafios e proposições sobre o fracasso escolar
}

\author{
Fabrício Rodrigues de Moura \\ Universidade Tecnológica Federal do Paraná - Campo Mourão - PR - Brasil \\ Marilda Gonçalves Dias Facci \\ Universidade Estadual de Maringá - Maringá - PR - Brasil
}

\begin{abstract}
Resumo
O Ensino Superior é um campo em que o psicólogo vem ganhando espaço para atuar, principalmente para minimizar o fracasso escolar. Assim, o objetivo deste trabalho é analisar a atuação do psicólogo escolar no Ensino Superior e o posicionamento que este profissional assume diante do fracasso escolar, a partir dos fundamentos da Psicologia Histórico-Cultural. Para compreender esse processo analisamos o quadro atual do Ensino Superior no Brasil, a inserção do psicólogo escolar neste nível de ensino e apresentaremos uma pesquisa realizada com 13 destes profissionais. Por fim, expomos algumas propostas de atuação: intervenção com alunos monitores; na recepção de calouros; com movimentos estudantis e na intervenção com gestores, coordenadores de curso e professores. Concluindo, compreendemos que a atuação do psicólogo escolar no Ensino Superior deve buscar a superação dos modelos tradicionalmente adotados pautados na culpabilização, fragmentação e individualização do fracasso escolar, efetivando práticas que busquem a emancipação dos indivíduos.
\end{abstract}

Palavras-chave: Ensino Superior; Psicologia Escolar; Psicologia Histórico-Cultural.

\section{The role of the school psychologist in higher education: settings, challenges and proposals about school failure}

\begin{abstract}
Higher education is a field in which the psychologist is becoming more popular to act, especially to minimize school failure. The objective of this study is to analyze the role of the school psychologist in higher education and the position that this professional takes face to face the failure in school, from the fundamentals of Historical-Cultural Psychology. To understand this process we analyze the current situation of higher education in Brazil, the inclusion of a school psychologist in this level of education and present a survey of 13 of these professionals. Finally, we show some action proposals: intervention with student monitors; at the reception of freshmen; with student movements and intervention with managers, course coordinators and teachers. In conclusion, we understand that the role of the school psychologist in higher education should seek to overcome the models traditionally adopted guided by the scapegoating, fragmentation and individualization of school failure, making effective practices that seek the empowerment of individuals.
\end{abstract}

Keywords: Higher Education; School Psychologist; Historical-Cultural Psychology

\section{La actuación del psicólogo escolar en la enseñanza superior: configuracio- nes, retos y proposiciones sobre el fracaso escolar}

\section{Resumen}

La Enseñanza Superior es un campo en que el psicólogo sigue ganando espacio para actuar, principalmente para disminuir el fracaso escolar. Así, el objetivo de este estudio es analizar la actuación del psicólogo escolar en la Enseñanza Superior y el posicionamiento que este profesional asume delante del fracaso escolar, a partir de los fundamentos de la Psicología Histórico-Cultural. Para comprender ese proceso se analizó el cuadro actual de la Enseñanza Superior en Brasil, la inserción del psicólogo escolar en este nivel de enseñanza y se presentó una investigación realizada con 13 de estos profesionales. Por fin, se expones algunas propuestas de actuación: intervención con alumnos monitores; en la recepción de novatos; con movimientos estudiantiles yen la intervención con gestores, coordinadores de curso y profesores. Concluyendo, comprender que la actuación del psicólogo escolar en la Enseñanza Superior debe buscar la superación de los modelos tradicionalmente adoptados pautados en la culpabilidad, fragmentación e individualización del fracaso escolar, efectivizando prácticas que busquenla emancipación de los individuos.

Palabras clave: Enseñanza Superior; Psicología Escolar; Psicología Histórico-cultural 


\section{Introdução}

Pensar a profissão de psicólogo nos dias atuais se torna cada vez mais importante, uma vez que a cada momento surgem novos campos de atuação. A demanda por profissionais da Psicologia tem aumentado e campos que até então não tinham a presença do psicólogo buscam cada vez mais a sua contribuição. Podemos citar o exemplo da Psicologia nas políticas sociais, nos direcionamentos relacionados ao trânsito, no meio ambiente, nos hospitais, na esfera do direito etc. Além dessas, áreas já tradicionais se fortalecem e ampliam possibilidades de atuação.

Um desses campos que ampliam as possibilidades de atuação é a Psicologia Escolar e Educacional. O profissional desta área atua tradicionalmente na Educação Infantil, Ensino Fundamental e Médio, com atividades como a avaliação psicoeducacional, a formação de professores, a orientação profissional, a gestão escolar e a formação docente. Por outro lado, surgem espaços de atuação emergentes, como as políticas públicas educacionais, pós-graduação e o Ensino Superior (Serpa \& Santos, 2001; Cunha \& Carrilho, 2005; Marinho-Araújo \& Bisinoto, 2011; Marinho-Araújo, 2009; Sampaio, 2011; Silva \& cols., 2013; Zavadski, 2009; Zavadski \& Facci, 2012; Cury, 2012). Esse último desperta-nos interesse especial, sendo a temática que será analisada neste estudo.

O contexto do Ensino Superior brasileiro atual é caracterizado pela expansão, sobretudo em função da privatização e massificação, tendo um ensino voltado à formação para o mercado de trabalho, entregue aos ideais mercadológicos, que nem sempre apresenta qualidade e ainda massifica a formação de graduação e precariza este nível de ensino (Chauí, 2003; Saviani, 2010). É nesse contexto que se insere o psicólogo escolar, para lidar com o fracasso escolar, conforme veremos.

A partir da década de 1990, o número de matrículas e de Instituições de Ensino Superior (IES) cresceu consideravelmente. Em 1996, o número de IES era de 922, enquanto em 2011 ampliou para 2.365. De 1990 a 2013 houve um crescimento de $474,39 \%$ no número de matrículas em instituições presenciais de Ensino Superior - de 1.540.080 para 7.305.977. Porém, grande parte do total de matrículas encontra-se em instituições privadas, que tiveram um salto de 558,88\% nesse período. No ano de 2013 as matrículas neste setor (5.373.450) representavam mais do que $73 \%$ do total, o que mostra maior participação do que no ano de 1990 (961.455), que tinha 62,42\% do total. (Censo da Educação Superior, Instituto Nacional de Estudos e Pesquisas Educacionais Anísio Teixeira, INEP, 2013b).

Apesar desse crescimento, o número de vagas que não foram preenchidas também aumentou. O Censo da Educação Superior de 2011 (INEP, 2013a) mostra que as IES disponibilizaram 3.228.671 vagas, mas somente 1.686.854 foram ocupadas no mesmo ano. Ou seja, $48 \%$ das vagas disponibilizadas ficaram ociosas. Ademais, desse total, 2.743.728 encontravam-se em instituições privadas e 484.943 nas públicas. Nestas, 426.597 foram ocupadas, já nas primeiras apenas 1.260 .257 . Isso representa mais do que $54 \%$ de vagas desocupadas na iniciativa privada e apenas $12,03 \%$ nas instituições públicas.

Outro fato a considerar para descrever a massificação e o fracasso escolar no Ensino Superior está relacionado ao ensino à distância (EAD). Em 2005 foram 13.469 matrículas nessa modalidade, já em 2010 esse número aumentou para 43.905 , com um crescimento de $226 \%$, conforme dados analisados por Silva Junior e Sguissardo (2012).

Assim, podemos considerar que tal ampliação ocorreu em função da precarização e privatização do ensino, pois, a partir da década de 1990 o Brasil aderiu definitivamente à política neoliberal, empregando os princípios dela no contexto educacional. Uma das consequências foi a massificação da educação universitária, levando à baixa qualidade do ensino e à formação em larga escala para preparar mão de obra para o mercado de trabalho. Além disso, facilitou a ampliação da iniciativa privada neste setor, o que levou a um aumento significativo de empresas de cunho educacional, conforme destaca Mata (2005).

O aumento de vagas não significa que os estudantes estejam tendo êxito no processo de ensino e aprendizagem, pois o fracasso escolar está presente no Ensino Superior. Por fracasso escolar no Ensino Superior entendemos a não apropriação dos conhecimentos científicos historicamente acumulados por alunos na sala de aula, em uma instituição ou em um sistema educacional. Neste nível de ensino, o fracasso escolar revela-se da seguinte forma: índices altos de reprovação, evasão e desistência; vagas insuficientes no setor público para atender a população; e formação massificada destinada a atender as demandas do mercado de trabalho e não buscando a utilização do conhecimento para uma sociedade justa.

Assim, o objetivo principal deste trabalho é discutir a atuação do psicólogo escolar no Ensino Superior que atua frente ao fracasso escolar. Verificaremos que psicólogos escolares que trabalham em instituição de Ensino Superior, por vezes, sentem-se confusos em relação à atividade a ser desenvolvida. Além disso, existem poucos estudos sobre esse assunto ${ }^{1}$, o que nos faz compreender que o tema apresenta relevância para a própria ciência pesquisada. Assim, como mostra Tomanik (2004, p. 16), "os conhecimentos reunidos sob o título de ciência são recursos desenvolvidos pelo homem, através da história, para suprir suas necessidades e aspirações". Dessa forma, até pouco tempo não havia necessidade de estudar a atuação do psicólogo escolar no Ensino Superior, simplesmente porque não existia este profissional atuando neste nível de ensino - atualmente a situação é diferente.

Desse modo, para atender ao objetivo proposto neste estudo, utilizamos como procedimentos metodológicos a pesquisa bibliográfica e realização de entrevistas.A primeira foi feita por meio da análise das políticas educacionais para o Ensino Superior a partir da década de 1990, especialmen-

1 Serpa \& Santos, 2001; Cunha \& Carrilho, 2005; Marinho-Araújo \&Bisinoto, 2011; Marinho-Araújo, 2009; Sampaio, 2011; Silva \& cols., 2013; Zavadski, 2009; Zavadski \& Facci, 2012; Cury, 2012. 
te aquelas que visam reduzir a reprovação e evasão, bem como ocupar vagas ociosas com alunos de baixa renda, pois entendemos que são esses os motivos que estão levando o psicólogo a atuar nesta área, respondendo ao fracasso escolar no Ensino Superior, assim como ocorreu e ocorre na educação básica. Além disso, realizamos um levantamento bibliográfico referente à atuação do psicólogo no Ensino Superior. Para a segunda parte utilizamos dados de uma pesquisa realizada com 13 psicólogos que atuam no Ensino Superior, principalmente aqueles que estão exercendo a profissão em uma instituição que aderiu ao Plano de Reestruturação e Expansão das Universidades Federais - REUNI².

\section{Psicologia Escolar e Educacional: relações com o fracasso escolar no Ensino Superior}

Nos últimos anos alguns estudos começam a surgir acerca da atuação do psicólogo no Ensino Superior, mas, assim como em outras áreas, estão longe de apresentar um panorama consensual sobre as atividades que esse profissional pode realizar. Alguns temas abordados são: adaptação do estudante, orientação e acompanhamento psicológico, recepção e acolhimento de novos alunos, formação de professores etc. (Serpa \& Santos, 2001; Cunha \& Carrilho, 2005; Marinho-Araújo \&Bisinoto, 2011; Marinho-Araújo, 2009; Silva, e cols., 2013; Sampaio, 2011; Zavadski, 2009; Zavadski \& Facci, 2012; Cury, 2012; Moura, 2015).

Segundo Marinho-Araújo e Bisinoto (2011), as primeiras abordagens do psicólogo neste nível de ensino surgiram na Europa, por meio dos Serviços de Apoio Psicopedagógico. A atuação era centrada na "intervenção individual com os estudantes, focada nos problemas que os levam a procurar ajuda profissional..." (p. 196). $\quad$ Em Portugal, por exemplo, no início dessa atividade existia a Rede de Serviços de Apoio Psicológico no Ensino Superior (RESAPES), responsável por intervir na graduação. No Brasil, porém, a atuação do psicólogo no Ensino Superior é menos tradicional do que na Europa; contudo, as experiências europeias influenciaram o desenvolvimento dessa área, tanto em relação à intervenção pautada no atendimento de modelo clínico, quanto como os Serviços de Apoio Psicopedagógico, que se inseriram no país com grande força, conforme veremos posteriormente.

Oficialmente é difícil relatar quando o psicólogo se insere na Educação Superior no Brasil. Tanto em pesquisas quanto em documentos oficiais não é claro o período em que esse profissional é convocado para atuar neste nível de ensino. Entretanto, segundo Marinho-Araújo e Bisinoto (2011), a Universidade de Brasília (UnB) tem o psicólogo escolar

2 O projeto REUNI é um Plano de Reestruturação e Expansão das Universidades Federais instituído pelo Decreto $\mathrm{n}^{\circ} 6.096$, do dia 24 de abril de 2007, como parte do Plano de Desenvolvimento da Educação. De acordo com as diretrizes gerais do Projeto, a meta global do REUNI é elevar a taxa de conclusão média dos cursos de graduação presenciais em $90 \%$ e estabelecer a relação de 18 alunos por professor em cursos presenciais ao final de cinco anos (Ministério da Educação, 2007). como parte da equipe desde 1999. Em relação ao ensino privado podemos citar um estudo feito por Santos (1997), que realizou uma pesquisa em uma universidade particular, sobre a dificuldade de compreensão em leitura em 44 alunos, por meio de um teste psicológico. Assim, mesmo não tendo registro de quando a presença do psicólogo ocorre no Ensino Superior no Brasil, há evidências nesses estudos de que ele atua desde a década de 1990.

No cenário atual, os psicólogos se encontram em setores destinados ao atendimento dos alunos como, por exemplo, o Serviço de Orientação ao Universitário (SOU) e o Serviço de Assistência ao Universitário (SAU), como destaca Marinho-Araújo (2009). Comumente a atuação do psicólogo tem foco individual, relacionado ao acompanhamento e atendimento dos acadêmicos, especialmente quanto a problemas verificados no âmbito da adaptação à vida universitária e às novas relações sociais; à insatisfação com a escolha do curso e da profissão; e a questões ligadas diretamente aos processos de ensino e aprendizagem relatados como distúrbios de concentração, falta de motivação, desorganização, não adaptação às metodologias de ensino. (Marinho-Araújo, 2009).

Em relação às pesquisas realizadas sobre a atuação do psicólogo escolar no Ensino Superior, podemos destacar que ainda é um campo pouco explorado e está longe de apresentar consenso sobre o papel desse profissional neste nível de ensino. Em algumas delas é possível identificar a legitimação de uma postura clínica, distante da discussão sobre os processos de ensino e aprendizagem, por exemplo. É o caso do estudo realizado por Serpa e Santos (2001) que pesquisaram acerca dos serviços de atendimento oferecidos aos universitários, com ênfase na atuação do psicólogo, em 61 instituições de Ensino Superior brasileiras, sendo 38 delas públicas, 10 privadas e 13 comunitárias. Em 31 dessas instituições o psicólogo estava presente, atendendo individualmente os alunos, sendo que: 96,8\% realizavam orientação individual, 51,6\% psicoterapia breve individual e $77,4 \%$ acompanhamento individual. Além disso, as autoras destacam o papel do psicólogo no Ensino Superior como privilegiado, não pela possibilidade de atuar com as questões que norteiam a educação, mas porque problemas de diversas ordens são demandas, "como uma formação básica insuficiente ou inadequada, falta de habilidades de leitura, escrita e estudo, insegurança nas tomadas de decisões." (Serpa e Santos, 2001, p. 29).

Outra pesquisa que também apresenta tal concepção é a desenvolvida por Cunha e Carrilho (2005), que atribuem as dificuldades encontradas por estudantes no Ensino Superior à fase de transição da adolescência para a vida adulta. Segundo as autoras, o confronto da identidade de adolescente com as exigências da vida universitária compõe um desafio para o estudante. Por isso, tais acadêmicos necessitam de uma atenção especial, por meio do atendimento psicológico.

Consideramos que esses estudos evidenciam o caráter individualizante e fragmentado dos atendimentos. Apesar das pesquisas de Cunha e Carrilho e de Serpa e Santos 
(2001) serem feitas há alguns anos, podemos inferir que o caminho que está sendo percorrido pela Psicologia é aquele semelhante às concepções tradicionais dessa ciência na educação básica, comprometida com o ideário burguês, desenvolvida a partir da psicometria e tomando como referência um modelo naturalizante, perspectiva anunciada por Patto (1990), desde os anos de 1980.

Essas perspectivas individualizantes são corroboradas quando observamos as políticas educacionais para o Ensino Superior. Como exemplo, podemos citar o Plano de Reestruturação das Universidades Federais - REUNI ${ }^{3}$. Segundo as diretrizes deste programa (Ministério da Educação, 2007), as instituições participantes recebiam recursos financeiros que poderiam ser destinados para a contratação de técnico-administrativos e docentes, bem como para a construção de salas de aulas, bibliotecas e laboratórios. Em contrapartida abriram cursos já preestabelecidos pelo Ministério da Educação (MEC) e deveriam atingir as metas propostas pelo programa. Dentre as ações que as IFES deveriam se comprometer está a implantação de políticas de inclusão, programas de assistência estudantil e políticas de extensão universitária.

Exemplos de algumas IES que sugerem o papel do psicólogo nesse processo, na dimensão no termo de pactuação, podem ser observados na Universidade Tecnológica Federal do Paraná - UTFPR, Universidade Federal de Santa Maria - UFSM e Universidade Federal de Santa Catarina - UFSC ${ }^{4}$. Para reduzir as taxas de evasão, a UTFPR estabeleceu algumas metas, e dentre elas está a de "Implantar o Núcleo de Apoio Psicopedagógico em todos os campi, contratando profissionais especializados para prestar atendimento psicológico e acompanhamento pedagógico aos discentes, servindo de apoio às coordenações de curso" (UTFPR, 2007, p. 29, grifos nossos). Já a UFSM estabelece como uma das metas para reduzir as taxas de evasão: "Programa de apoio pedagógico, social e psicológico ao corpo discente (Ânima). Ampliação do atendimento do ÂNIMA para o turno noturno" (UFSM, 2007, p. 19). E a UFSC estabelece como um dos programas de assistência estudantil a implantação de "Programas de Prevenção e Atenção a Saúde Mental dos Estudantes", com a contratação de psicólogo, psiquiatra, assistente social e enfermeiro (UFSC, 2008).

Vemos nesses termos de pactuação dessas universidades, assim como nas pesquisas realizadas, que a função do psicólogo está relacionada à redução das taxas de reprovação e evasão e também a de melhorar o desempenho dos estudantes, por meio de atendimentos e acompanhamento

\footnotetext{
3 Tal plano tem como objetivo oferecer condições necessárias para ampliação do acesso e permanência dos estudantes na Educação Superior nas universidades participantes do plano. De acordo com as diretrizes gerais do projeto, a meta global é elevar a taxa de conclusão média dos cursos de graduação presenciais em $90 \%$ e estabelecer a relação de dezoito alunos por professor em cursos presenciais ao final de cinco anos (Ministério da Educação, 2007).

4 Escolhemos essas instituições a partir da busca eletrônica via internet pelos termos de pactuação de metas das Universidades Federais que aderiram ao REUNI e que apresentavam o serviço de psicologia como proposta para atingir as metas do plano.
}

dos alunos. Ou seja, a lógica é: a evasão e o desempenho dos alunos não são bons porque passam por "problemas" psicológicos. Se tiverem atendimento/acompanhamento do psicólogo não se evadirão e o desempenho será melhor.

Por meio dessas descrições vemos que a Psicologia Escolar e Educacional parece ter um papel bem definido socialmente, ao menos ideologicamente: tratar e resolver problemas que se concentram nos indivíduos. Desse modo, é difícil esperar que esse profissional atue de maneira crítica, buscando o desenvolvimento humano e a apropriação do conhecimento científico por parte dos alunos, pois a concepção presente nesses documentos é de um profissional fechado em sua sala de atendimento, atendendo alunos que não atingem os resultados esperados, o que está muito próximo de uma concepção de clínica de atuação. Assim, o fracasso escolar é visto como fracasso individual e o psicólogo mais uma vez é instrumento de corroboração desta concepção.

A seguir apresentaremos, a título de exemplo, uma pesquisa realizada com psicólogos escolares que atuam no Ensino Superior.

\section{A atuação do psicólogo escolar no Ensino Superior: uma amostra do panorama atual}

No ano de 2014 fizemos uma pesquisa com 13 psicólogos que atuam no Ensino Superior, contratados por quatro Universidades Federais, sendo duas situadas no Paraná, uma no Rio Grande do Sul e uma em Santa Catarina ${ }^{5}$.

Para chegar a esses profissionais, fizemos um levantamento via internet dos termos de pactuação apresentados ao MEC pelas instituições. Encontramos doze desses documentos disponíveis. Após esse levantamento, analisamos quais universidades apresentavam o serviço de Psicologia como proposta para atingir as metas do REUNI, ou seja, para reduzir o fracasso escolar. Assim, chegamos ao número de seis instituições que contavam com esse profissional no documento. Quatro delas aceitaram participar do processo. Portanto, contatamos os profissionais que atuavam nessas instituições por telefonemas e agendamos as entrevistas. As universidades participantes pertencem a quatro Estado: duas situadas no Paraná, uma no Rio Grande do Sul e uma em Santa Catarina ${ }^{6}$.

As entrevistas foram semiestruturadas, ou seja, seguiram um roteiro básico, organizado em dois eixos. O primeiro buscou realizar um levantamento do perfil dos psicólogos, contendo informações como sexo, idade, ano e local da formação, experiência profissional e tempo de trabalho no Ensino Superior. O segundo buscou obter informações relacionadas à prática profissional e às concepções sobre a Psicologia no Ensino Superior.

\footnotetext{
5 A pesquisa foi aprovada pelo Comitê Permanente de Ética em Pesquisa Envolvendo Seres Humanos da Universidade Estadual de Maringá, por meio do parecer 502.240.

6 Conforme solicitação das instituições, elas não serão caracterizadas tampouco nomeadas.
} 
O resultado das entrevistas mostra que o perfil dos entrevistados se caracteriza por serem mulheres com idade inferior a 33 anos e formados há menos de 10 anos. Quanto à qualificação dos profissionais, constatamos que as áreas de especialização dos entrevistados são variadas, que vão desde recursos humanos até o mestrado em Psicologia do desenvolvimento e aprendizagem. Todos os entrevistados estão vinculados a um órgão que trabalha diretamente com a educação, seja por meio da assistência ao aluno ou diretamente a um órgão educacional, como o departamento de educação.

Constatamos que a maioria dos psicólogos (76,9\%) está atuando em uma divisão que realiza ações diretamente com os alunos (apoio ao estudante, assuntos estudantis, assistência estudantil). Isso se confirma quando observamos que $84,59 \%$ têm como alvo de intervenção somente alunos, ou seja, pouco mais de $15 \%$ deles trabalham com outros públicos, como os professores, por exemplo. Tais verificações assinalam para objetivos de trabalho e as ações também são voltadas para os discentes. Além disso, a maioria relata que o objetivo do trabalho tem uma ligação direta com a permanência dos alunos na instituição e com a diminuição dos índices de evasão da universidade, sendo $61,52 \%$ das respostas nesse sentido.

Entendemos que a atuação com foco nos discentes não é, necessariamente, um agravante, afinal são os alunos que serão os futuros profissionais formados pela instituição. O que compreendemos ser uma atuação que culpabiliza e rotula os acadêmicos como responsáveis pelo fracasso escolar é aquela pautada na intervenção individual. Parece-nos que é essa característica da maioria dos psicólogos entrevistados. Constatamos que 92,28\% realizam atendimento individualizado, semelhante a um trabalho de aconselhamento e/ ou psicoterapia breve. Somente $7,69 \%$ atuam junto a professores, oferecendo orientação em relação aos alunos.

$\mathrm{O}$ atendimento individualizado produz uma grande procura por intervenção psicológica. Assim, para dar conta da quantidade de atendimentos alguns profissionais relatam que fazem "plantão psicológico", ou seja, destinam um horário exclusivo para atender os alunos. Um psicólogo explica o que é o plantão: "Nós temos dias e horários de plantão... Ele é para várias situações de emergência, enfim, para situações em que o aluno não está se sentindo bem por algum motivo, ele pode vir e conversar conosco" (grifos nossos). Nesse contexto, quando questionados sobre as dificuldades encontradas no trabalho, 30,76\% dos psicólogos acreditam que elas estão relacionadas a uma grande demanda de atendimentos para a Psicologia, relatando que o número de psicólogos é insuficiente para o trabalho.

O plantão psicológico, descrito acima, expressa o modo como os profissionais tentam resolver a questão da alta demanda por atendimento. Ou seja, de modo individual, com base em uma perspectiva clínica da Psicologia Escolar e Educacional e de acordo com a demanda, ou seja, independente de planejamentos e objetivos.

Fazendo uma contextualização dos fatos que podem levar a tal prática, consideramos que os psicólogos entrevistados também são agentes de produção e reprodução do modelo social e, por isso, nem sempre se apresentam esclarecidos em relação à forma com que exercem suas práticas. O modo capitalista de compreender o homem parte de um pressuposto de adaptação ao meio, segundo o qual aqueles que se adaptam são produtivos e os que não se enquadram apresentam algum problema, de cunho orgânico ou mental, passível de tratamento. Segundo Vigotski (2010), a transmissão dessa maneira de pensar ocorre por meio da ideologia. Esse conceito é assim definido pelo autor: "chamamos de ideologia todos os estímulos sociais que se estabeleceram no processo de desenvolvimento histórico que se consolidam sob a forma de normas jurídicas, regras morais, gostos estéticos, etc." (Vigotski, 2010, p. 286). Incluímos nessas formas a educação, a política e as leis, pois é por essas formas que os psicólogos entrevistados foram inseridos no contexto em que estão atuando.

É nesse contexto que os psicólogos formarão suas bases teóricas e práticas para atuar, com a ideologia comprometendo o modo de entender a própria atuação profissional. Entretanto, isso não fica evidente para os entrevistados, que atribuem a falta de compreensão da função do psicólogo a outros profissionais da educação. Grande parte $(53,83 \%)$ considera que existe falta de entendimento em relação ao trabalho do psicólogo por parte dos gestores, professores, servidores e alunos da universidade. Zavadski e Facci (2012), ao entrevistarem professores do Ensino Superior, também constataram que os docentes não compreendem o trabalho do psicólogo no Ensino Superior, tendo uma expectativa de trabalho clínico.

Apesar desse relato por parte dos entrevistados, a falta de entendimento em relação ao trabalho da Psicologia no Ensino Superior por outros profissionais da educação se estende aos próprios psicólogos. Um dos entrevistados relata, no entanto, que a maior dificuldade é entender o que deve fazer como profissional da Psicologia: "essa eu acho que é a grande dificuldade, é entender o que que eu faço ali dentro, o que que eu posso fazer ali dentro". Outro descreve que realiza um tipo de atuação, mas acredita que deveria fazer outra: "geralmente a minha atuação é mais direta com aluno, na prática, apesar de eu achar que eu cumpriria mais o meu papel trabalhando mais direto com o professor". A resposta de mais um entrevistado também evidencia isso, deixando claro que precisa entender melhor o papel da Psicologia no Ensino Superior: "Eu acho que, uma das coisas que eu mais vejo é qual o papel da psicologia, eu tenho muita dificuldade de entender" (grifos nossos).

Vemos, desse modo, que mesmo que a maioria dos psicólogos atue de modo individualizado, semelhante à clínica, existe uma preocupação em modificar essa prática. Parece que os profissionais entrevistados sabem que precisam mudar de postura, mas não sabem como, nem o que modificar. Tal fato se comprova quando constatamos que grande parte deles $(53,83 \%)$ entende que o fracasso escolar no Ensino Superior é resultado de um ensino básico insuficiente. Além disso, o alto índice de cobrança do Ensino Superior e a dificuldade das disciplinas são destacados por $38,45 \%$ dos profissionais como fator de causa do fracasso. 
Em relação às possibilidades de atuação do psicólogo diante da realidade do fracasso escolar, as propostas apresentadas foram bem difusas e diferentes, que vão desde uma intervenção no sentido de baixar a ansiedade dos alunos até a de realizar um trabalho institucional com a gestão, docentes e alunos. Somente $7,69 \%$ relataram que se deve fazer uma análise da instituição a respeito das questões de ensino e $23,07 \%$ dos entrevistados propõem trabalhar diferente do modo como o psicólogo atua na educação básica. Nesses casos, os profissionais concebem o trabalho neste nível de ensino como aquele pautado em atendimentos clínicos, na orientação de alunos.

A partir desta pesquisa observamos que a Psicologia Escolar e Educacional no Ensino Superior ainda não construiu bases teóricas e práticas para sua consolidação. Quando questionados em relação à necessidade de mudar a atuação profissional, 92,28\% relatam que é necessário modificar. Apesar disso, quando interrogados sobre o que era preciso alterar, os entrevistados não apresentaram respostas unânimes, responderem de formas bem variadas, sendo que $23,07 \%$ do total acreditam que devem ter maior envolvimento com a instituição como um todo; do mesmo modo, $23,07 \%$ entendem que é preciso trabalhar mais com grupos e oficinas; e 15,38\% relatam que é imprescindível tanto estabelecer mais diálogo com as coordenações de curso quanto estar mais próximo ao corpo docente.

Assim, observamos que os psicólogos entrevistados expressam a necessidade de mudança na atuação, o que pode revelar que o modo que estão atuando não tem produzido resultados satisfatórios. Conforme já vimos, grande parte deles atua de modo individual, com foco no aluno, desconsiderando o contexto educacional, porém, parece que o desejo de mudar essa perspectiva de atuação está presente nos anseios expressos pelos profissionais.

Desta forma, apresentamos, a seguir, algumas possibilidades de intervenção frente ao fracasso escolar.

\section{Iniciando um debate: formas de atuação do psicólogo escolar que buscam a superação do fracasso escolar}

Consideramos que é importante que o psicólogo estude e entenda os processos educacionais relacionados ao Ensino Superior, assim como o desenvolvimento e aprendizagem do jovem - público majoritariamente presente neste nível de ensino. Para tanto, temos como concepção teórica que auxilia na compreensão crítica das questões educacionais, e do psiquismo humano, bem como o desenvolvimento e aprendizagem, a Psicologia Histórico-Cultural.

Nesta perspectiva teórica a transformação do homem vai para além do seu caráter biológico, passa por mudanças psíquicas importantes, ou seja, não ocorre sem uma alteração qualitativa nas funções cerebrais. De acordo com Vygotsky ${ }^{7}$ e Luria (1996) com o domínio da natureza e o de-

7 Utilizamos a grafia de acordo com o que é descrito nas referências utilizadas. Desse modo, três grafias diferentes estão presentes: senvolvimento de instrumentos, o ser humano desenvolveu funções psíquicas qualitativamente superiores. É o caso da atenção, memória, abstração, pensamento, formulação de conceitos etc. A apropriação de tais funções permite ao homem se distanciar das condições biológicas e o conduz a um desenvolvimento cultural que possibilita o domínio sobre a natureza e dos instrumentos historicamente produzidos. A interação do homem com o meio não ocorre naturalmente após o nascimento. Com o crescimento, o mundo da criança se amplia e as relações estabelecidas com o meio social se modificam. Tais mudanças farão com que a ela se desenvolva e, com isso, alterações em seu psiquismo a colocarão em outro patamar de desenvolvimento. É por isso que identificamos estágios de desenvolvimento qualitativamente diferentes. Tais estágios dependem das condições históricas concretas. "A influência das condições históricas concretas exerce-se tanto no conteúdo concreto de tal ou tal estágio dado do desenvolvimento, como sobre o curso do processo de desenvolvimento psíquico no seu conjunto" (Leontiev, 2004, p. 312). É por isso que em determinados períodos históricos se contemplam diferentes épocas da vida.

Tolstji (1989) assinala que a Psicologia tem estudado mais sobre as crianças; entretanto, a construção teórica do desenvolvimento e da periodização infantil é a base para entendermos o desenvolvimento e a aprendizagem do jovem. Vygotski (1996) afirma que o desenvolvimento ocorre pelas relações que se estabelece com o meio social e que saltos qualitativos dependem pouco da cronologia da idade. As condições histórico-sociais, a forma como a sociedade se organiza em classes sociais antagônicas influenciarão esta ou aquela forma de vida.

Consideramos assim que a juventude é um período do nosso tempo e com características e atividade dominante também de nossa época. É o desenvolvimento social que produz a necessidade de caracterizar, estender ou criar uma fase: "a duração (das etapas do desenvolvimento) mudou de época para época, alongando-se à medida que cresciam as necessidades da sociedade neste tocante" (Leontiev, 2004, p. 312). Entendemos, assim, que a etapa de desenvolvimento denominada como juventude nessa sociedade é o primeiro estágio do período de maturidade, conforme diz Vygotski (1996); por outro lado, é também, a segunda etapa de transição para a maturidade (a primeira é a adolescência), conforme analisa Tolstij (1989), o que fará com que o desenvolvimento ocorra de forma diferente em cada indivíduo vai depender da qualidade em que se estabelecem as relações sociais. A periodização tem como elemento central a condição histórica e social, que leva os indivíduos a ter uma forma específica de relação com a realidade, a uma atividade dominante.

O conceito de atividade dominante ${ }^{8}$ é fundamental para compreendermos o desenvolvimento desse público.

\footnotetext{
"Vygotsky", "Vygotski" e "Vigotski".

8 Alguns autores utilizam a expressão "atividade principal" ou "atividade guia" (Prestes, 2010). Optamos pelo termo "atividade dominante", pois a tradução dos livros utilizados neste trabalho empregam tal expressão.
} 
Segundo Leontiev (2004), alguns tipos de atividades têm maior importância em determinadas etapas da vida do que em outras. Em cada fase existe uma na qual ele se comunica, participa, se insere, compreende e atua de modo mais efetivo. Assim, um jovem que estuda e trabalha pode ter como atividade dominante o trabalho (geralmente a classe trabalhadora), sendo o estudo uma atividade secundária, enquanto que outros jovens que se dedicam exclusivamente ao curso superior, podem ter como atividade dominante o estudo e profissionalização.

Dados estatísticos demonstram que 4.813.301 jovens de 18 a 29 anos estavam matriculados no Ensino Superior e que a população dessa faixa etária no mesmo ano era de 30.982.604, ou seja, a taxa de jovens que não frequentam esse nível de ensino é de $84,46 \%$, segundo o IBGE (2011). Assim, esses jovens realizam outra atividade que não é a de estudo, mas possivelmente a atividade de trabalho. Já para os jovens que estão matriculados no Ensino Superior, a atividade dominante se modifica.

Dados de 2008 da Pesquisa Nacional por Amostra de Domicílios, mostrados por Nunes (2012), demonstravam que $70,5 \%$ dos estudantes do Ensino Superior trabalhavam durante o período de graduação e outros $29,5 \%$ não precisavam trabalhar. Considerando somente as IES particulares o número de alunos que trabalhavam sobe para $74,4 \%$. Nas IES públicas esse número cai, mostrando uma porcentagem de $57,2 \%$ de alunos trabalhadores. Isso mostra, segundo Nunes (2012, p. 190), que "o ensino superior privado é quem mais dá acesso aos egressos do ensino básico público, e que necessitam do trabalho para sustentar seus estudos". A partir dessas configurações podemos identificar dois grupos de jovens no Ensino Superior: os que se dedicam exclusivamente aos estudos e os que estudam e trabalham. Ambos os grupos devem encontrar, nas Universidades, possibilidades de formarem conceitos - guardadas as especificidades de cada curso de graduação - e de se desenvolverem psicologicamente.

Vigotski (2008) deixa claro que o ensino deve incidir sobre o nível de desenvolvimento próximo do aluno, ou seja, naquilo que ainda não está efetivado, o que pode ser realizado com a ajuda de pessoas mais experientes. Assim, é necessário que os alunos tenham condições necessárias para o aprendizado dos conceitos ensinados no Ensino Superior. O ensino deve ser encaminhado para o desenvolvimento máximo das potencialidades dos jovens.

Considerando que os dois grupos de jovens que expusemos podem apresentar condições mínimas diferentes, é necessário que a Instituição de Ensino Superior promova o desenvolvimento deles para que estejam em níveis semeIhantes no processo de ensino e aprendizagem ${ }^{9}$. Compreendemos que as Instituições de Ensino Superior e as pessoas envolvidas com o processo de ensino e aprendizagem (incluindo os psicólogos) necessitam realizar duas importantes ações para promover o desenvolvimento dos discentes: a

9 Entendemos que a Educação Básica deveria oferecer conhecimentos necessários para os alunos que ingressarão no Ensino Superior. Entretanto, isso não ocorre de modo efetivo e as IES não podem ignorar tal defasagem. primeira é a de cobrar sistematicamente dos órgãos competentes a qualidade da educação básica, que pode ser realizada por meio de estudos e pesquisas, divulgando-as nos poderes executivo e judiciário, por exemplo; a segunda é a de assegurar que os alunos que não têm conhecimentos esperados para a graduação possam contar com recursos educacionais que possibilitem a apropriação e o aprendizado dos conteúdos, o que pode ser feito por meio de programas de apoio e de nivelamento com conhecimentos básicos do Ensino Médio.

Nesse contexto de discrepâncias entre aqueles que frequentam o Ensino Superior é que o psicólogo atuará. Se o psicólogo almeja ter uma atuação que vise à aprendizagem dos universitários e, consequentemente, o desenvolvimento deles, é preciso ter claras as condições oferecidas pela sociedade e pelo ensino de graduação. Desse modo, entendemos que tanto os conhecimentos dos problemas que existem no Ensino Superior (evasão, repetência, por exemplo) quanto as teorias do desenvolvimento do jovem necessitam ser instrumentos teóricos desse profissional para a elaboração de práticas que busquem uma educação de qualidade e que ofereça condições para a apropriação do conhecimento historicamente acumulado, conforme destaca Saviani (2003). Assim, cabe ao psicólogo compreender o processo de desenvolvimento e aprendizagem relacionado às condições que os alunos têm para a apropriação do conhecimento, que vão desde a formação dos professores, a estrutura física oferecida pela universidade (biblioteca, laboratório etc.), a atividade dominante e, principalmente, a base material oferecida pela sociedade.

Conforme observamos acima, não existe um consenso sobre como o psicólogo escolar deve atuar no Ensino Superior. Fica evidente, porém, que há uma necessidade de mudança na atuação, que deve haver uma ampliação no trabalho, pois grande parte dos atendimentos é voltada para o aluno, com foco individual. Devemos almejar a apropriação do conhecimento, vagas suficientes para todos (socialização do conhecimento) e formação de qualidade. Em relação ao segundo item, consideramos que o trabalho do psicólogo pode ocorrer com a atuação política, por meio do desejo, da luta, da denúncia e do empenho por uma transformação da sociedade junto aos alunos e professores. Para garantir vagas suficientes para todos precisamos ter uma mudança radical no nosso sistema de ensino que, por sua vez, depende de uma transformação da base material.

Em relação aos outros itens - apropriação do conhecimento e formação de qualidade - compreendemos que é possível assinalar algumas práticas que contemplam a busca por essas importantes tarefas de um modo mais imediato. Para tanto, entendemos, assim como Tanamachi e Meira (2003, p. 43),que o psicólogo é um profissional que "pode ajudar a escola a remover obstáculos que se interpõem entre os sujeitos e o conhecimento...", pensando na coletividade, em práticas pedagógicas que possibilitem a formação de conceitos e um conhecimento mais crítico da realidade. Contribuir para remover os obstáculos que se interpõem entre os sujeitos para que o processo de apro- 
priação do conhecimento ocorra parece-nos um importante aspecto para o Ensino Superior.

Entendemos que é possível aproximar as pessoas envolvidas com ensino de modo a construir um processo pedagógico qualitativamente superior, que evidencie a coletividade do sistema educacional. Dessa forma, o trabalho do psicólogo escolar no Ensino Superior necessita contemplar o maior número de envolvidos no processo de produção e apropriação do conhecimento, desde direção, gestores, servidores e especialmente alunos e professores, aqueles que estão à frente da produção do ensino e da aprendizagem. Para isso, propomos quatro atividades que podem contribuir para a superação do fracasso escolar: o trabalho junto aos alunos monitores; a atividade de recepção aos calouros; a atuação junto a movimentos estudantis; e a mediação e intervenção com gestores, coordenadores de curso e professores.

Os programas de monitoria compõem o processo de ensino e aprendizagem do ensino de graduação e o psicólogo pode lançar mão das teorias do desenvolvimento e aprendizagem para auxiliar monitores. Entendemos que o conceito de zona de desenvolvimento próximo (Vigotski, 2000) é um elemento importante para esse fim, pois permite ao monitor pensar no nível de desenvolvimento próximo dos outros alunos para elaborar a monitoria, uma vez que uma pessoa que domina uma determinada teoria/conteúdo/ conceito melhor (o monitor) que outra (demais alunos), pode auxiliá-la a ponto levá-la a dominar tal teoria/conteúdo/conceito sozinha posteriormente.

Ademais, o psicólogo escolar pode auxiliar o monitor a realizar um planejamento dos conteúdos que devem ser explanados, a partir das dificuldades expostas pelos demais alunos (nível de desenvolvimento real), a fim de elaborar um roteiro de atividades a serem desenvolvidas (nível de desenvolvimento próximo) nos horários de monitoria. Isso se torna importante para que as ações não se tornem espontâneas, com a utilização do espaço somente para tirar dúvidas ou responder exercícios sem um planejamento adequado. Pode também ajudar o monitor no processo de ensino, fornecendo conhecimento sobre a linguagem a ser usada, na busca por conectar sentido e significado de um conteúdo (a que ele serve na prática) e na forma de expor os conceitos. O psicólogo também pode intervir ajudando a elaborar um documento com os conteúdos menos compreendidos por quem procura a monitor, com o propósito de apresentar ao professor responsável pela disciplina. Assim, o docente pode (re)pensar sua prática, didática e metodologia, buscando que a apropriação do conteúdo seja realizada por todos os alunos. Afinal, a monitoria nada mais é do que um apoio ao processo de ensino e aprendizagem que ocorre de fato em sala de aula.

Outra possibilidade de intervenção do psicólogo escolar no Ensino Superior é em relação à recepção aos calouros. Esta atividade já é algo tradicional nas Instituições de Ensino Superior (IES). Considerando os altos índices de evasão no Ensino Superior, 34,22\% segundo dados do Censo da Educação Superior ${ }^{10}$ de 2012 (INEP, 2014), e

10 Esse cálculo foi feito a partir das matrículas trancadas e desvinculadas dos cursos. que mais da metade desse índice ocorre no primeiro ano (Lobo, 2012), é interessante pensar na busca da superação do fracasso escolar por meio da intervenção com os alunos ingressantes. Entendemos que o psicólogo escolar pode contribui em relação à compreensão dos fenômenos que leva a desistência dos jovens discentes. Neste sentido, uma prática interessante foi realizada por Silva e cols. (2013), em que, a partir de um estágio supervisionado em Psicologia Escolar, desenvolveram um trabalho de acolhimento e orientação dos calouros do curso de Psicologia da Universidade Federal de Uberlândia (UFU). Uma vez que a maior desistência dos alunos ocorre no primeiro ano, entendemos que o acolhimento dos calouros, a explicação sobre como se desenvolve o curso, os debates em torno da formação profissional fornecem aos ingressantes conteúdos importantes para refletirem sobre a escolha profissional que fizeram e receberem apoio emocional (dos pais e de outros alunos). Desse modo, tal prática pode levar ao não abandono do curso precocemente, pois compartilha angústias e experiências vividas por outros acadêmicos.

Entendemos também que outras atividades podem ser desenvolvidas com os novos discentes, especialmente relacionadas ao processo de ensino e aprendizagem. Compreendemos que a intervenção do psicólogo escolar pode contribuir ainda mais em relação às possibilidades de superação do fracasso escolar no Ensino Superior. Nesse sentido, uma das ações que poderia ser realizada é o acompanhamento da aprendizagem dos ingressantes junto com os docentes. Isso poderia ser iniciado com uma avaliação investigativa sobre os conhecimentos que os alunos têm sobre os conteúdos que serão ensinados no primeiro bimestre - nível de desenvolvimento real (Vigotski, 2000). A partir disso, poderiam ser elencados junto aos professores quais os conhecimentos necessários para que os discentes se apropriem do conteúdo. Posteriormente, realizar reuniões semanais ou quinzenais com os acadêmicos para avaliar se os conhecimentos ensinados em sala de aula estão sendo aprendidos. E, por fim, analisar com o corpo docente se o resultado está sendo positivo ou se é necessário rever algum aspecto no processo de ensino e aprendizagem. Essa atividade poderia ser realizada pelo psicólogo escolar ao longo do primeiro semestre de aula. Formar novos conceitos mobiliza a transformação nas funções psicológicas superiores, tais como a atenção, a memória, o raciocínio, a capacidade de abstração, entre outras funções.

A alteração qualitativa nas funções cerebrais, a apropriação dos conceitos científicos e o desenvolvimento das funções psicológicas superiores ocorrem no jovem de modo mais efetivo que na criança. Entretanto, não é porque ele é um ser potencialmente mais elevado em suas condições psicológicas que isso ocorre de modo natural e espontâneo. Vygotski e Luria (1996) deixam claro que esse processo exige a mediação de outras pessoas, a apropriação da cultura e uma tomada de consciência do uso destas funções, passando de um processo natural para um processo mediado por instrumentos e signos criados pelos homens. Se as influências de condições externas não oferecerem possibili- 
dades para isso a capacidade superior de desenvolvimento do jovem pode ser prejudicada.

Assim, entendemos que é relevante destacar a importância do Ensino Superior para os novos alunos. Isso pode ser realizado concomitantemente ao acompanhamento da aprendizagem dos calouros. Compreendemos que unir sentido e significado é fundamental para que os novos alunos realizem suas atividades de forma não alienada. Se os acadêmicos compreenderem que a entrada na universidade é um momento de realizarem ações que não têm relação com o aprendizado de conhecimentos que serão importantes para a formação e para a profissionalização - o sentido que conferem à entrada da universidade (Leontiev, 2004) - poderá ocorrer uma cisão entre sentido e significado, produzindo um processo de alienação. Ou seja, o significado de fazer uma faculdade (se profissionalizar, adquirir conhecimento e cultura, ter uma profissão) não corresponde ao sentido (fazer amigos, morar fora de casa, ter independência dos pais etc.). Claro que essas ações são importantes na vida do jovem, desde que não sejam atreladas à realização do curso de graduação. A alienação pode ser responsável por um baixo desempenho, reprovação e evasão, ou seja, produz o fracasso escolar. Assim, é importante que o psicólogo escolar esteja atendo a esse fenômeno também.

Outra possibilidade de atuação do psicólogo escolar no Ensino Superior está relacionada ao trabalho junto aos movimentos estudantis. Nessa perspectiva, compreendemos que o psicólogo escolar pode atuar em dois focos. Em IES que não têm constituído o DCE e os CAs, ele pode fomentar e auxiliar os estudantes a organizarem-se para compor essas entidades. Outra intervenção possível ocorre quando já existem movimentos estudantis constituídos na universidade. Compreendemos que a participação dos estudantes na composição de políticas, programas, decisões administrativas e, mais especificamente, na organização do processo de ensino e aprendizagem é de fundamental importância. O passo inicial para essa participação pode partir do psicólogo escolar intermediando junto à direção da IES e das coordenações de curso. Após esse processo é necessário que os estudantes se organizem de modo a elencar as principais reivindicações, pois quando não há planejamento e organização o movimento se enfraquece e as pautas são difusas e confusas. Para que isso ocorra, o profissional da Psicologia pode participar das reuniões do DCE e CAs a fim de auxiliar e discutir as necessidades da instituição e dos cursos.

Por fim, entendemos que os acadêmicos necessitam ser protagonistas de atividades de cunho artístico, cultural e educacional na IES. Desse modo, o psicólogo contribui auxiliando no desenvolvimento dessas atividades, que têm como exemplos: a confecção de um jornal da universidade ou de um curso; a exibição de peças teatrais dentro do espaço universitário; a organização de palestras, eventos e congressos; elaboração de festivais culturais etc. Isso porque compreendemos que o desenvolvimento humano é ilimitado e que a criatividade é um elemento essencial nesse processo, por isso a expressão artística é indispensável para a formação humana. Vigotski (2010), assim escreve que «De coisa rara e fútil a beleza deve transformar-se em uma exigência do cotidiano" (p. 352, grifos nossos).

Para finalizar nossa contribuição em relação às possibilidades de atuação do psicólogo escolar no Ensino Superior, apresentaremos uma proposta de intervenção junto aos gestores, coordenadores de curso e professores que tem por objetivo fazer cumprir a função social da educação, a de socializar o conhecimento historicamente acumulado (Saviani, 2003). Para tanto, entendemos que esse público é o responsável por elaborar e efetivar as práticas institucionais relacionadas ao ensino; a ação destes educadores deve ter como finalidade comum levar o aluno a se apropriar dos conhecimentos de determinada ciência. Segundo Leontiev (2004), as atividades são os procedimentos realizados com o objetivo de alcançar o motivo inicial que a incitou. Ou seja, os gestores, coordenadores de curso e docentes precisam compreender que as atividades executadas devem caminhar para a finalidade a qual se destina, no caso do Ensino Superior, formar alunos que dominem os conhecimentos de uma determinada ciência e saibam aplicá-los no exercício da profissão.

Entendemos, assim, que o psicólogo escolar pode intervir junto a esse público de modo que busquem a efetividade de suas atividades, relacionando-as com a apropriação do conhecimento por parte dos discentes. Zavadski e Facci (2012) propõem um modelo de atuação do psicólogo na formação de professores, "instrumentalizando-os acerca do processo de desenvolvimento e aprendizagem dos alunos... Levar o professor a compreender que ele tem possibilidade, com o seu trabalho, de contribuir para o processo de humanização dos alunos" (p. 695). Ainda segundo essas autoras, o professor universitário não vem tendo uma formação adequada para o exercício da prática pedagógica, ficando o ensino baseado na sua experiência como aluno. Isso não leva somente a um quadro de não aprendizagem por parte dos alunos, mas também a um processo de alienação em relação ao seu trabalho.

Segundo Asbahr (2005), o sentido e o significado social da atividade pedagógica precisam estar intimamente relacionados para que o processo de alienação não ocorra. A autora entende que o significado social da atividade pedagógica "é proporcionar condições para que os alunos aprendam, ou melhor, engajem-se em atividades de aprendizagem" (Asbahr, 2005, p. 113). Se o sentido pessoal que os docentes atribuem à sua atividade não for condizente com o significado social da sua prática ocorre uma cisão, produzindo limitações no trabalho, desânimo, frustração e alienação. Para integrar sentido e significado Asbahr (2005) propõe que a elaboração do Projeto Político Pedagógico (PPP) na Educação Básica possibilite aos docentes a organização e o entendimento de suas práticas, bem como a reflexão em relação aos motivos que os levam a realizar a atividade docente. No Ensino Superior, a integração de sentido e significado poderia ser promovida na elaboração do Plano de Desenvolvimento Institucional (PDI) - documento que define os objetivos da IES; do Projeto Pedagógico de Curso (PPC) - que estabelece as diretrizes curriculares do curso e as pro- 
postas de ensino e aprendizagem; e dos Planos de Ensino - que definem conteúdos, metodologias e planejamento de uma disciplina.

O psicólogo escolar pode auxiliar os gestores, coordenadores de curso e docentes na elaboração desses documentos com seus conhecimentos em relação ao processo de desenvolvimento, ensino e aprendizagem. Assim, acreditamos que a intervenção se pautaria em um modelo crítico e emancipador da prática da Psicologia Escolar e Educacional.

\section{Considerações finais}

Compreendemos que a atuação do psicólogo escolar no Ensino Superior deve buscar a superação dos modelos tradicionalmente adotados pela ciência psicológica pautados na culpabilização, fragmentação e individualização do processo de ensino e aprendizagem. Entendemos o psicólogo escolar

como um elemento mediador que - junto com educadores, alunos, funcionários, direção, famílias e comunidade - poderá avaliar criticamente os conteúdos, métodos de ensino e as escolhas didáticas que a escola faz como um todo. Assim, ele pode participar de um esforço coletivo voltado para a construção de um processo pedagógico qualitativamente superior, fundamentado em uma compreensão crítica do psiquismo, do desenvolvimento humano e de suas articulações com a aprendizagem e as relações sociais (Tanamachi \& Meira, 2003, p. 53, grifos nossos).

Atuando de forma coletiva, considerando os diversos atores envolvidos no processo educacional, é possível almejar mudanças tanto na prática profissional quanto na possibilidade de contribuir para a construção de um modelo educacional e social diferente do que temos.

Nosso artigo buscou oferecer um conhecimento relacionado à prática do psicólogo escolar no Ensino Superior, que surgiu de uma necessidade prática - afinal esse é um campo novo de atuação para a Psicologia e ainda sem muitos estudos - e que precisa agora, voltar-se para a prática para se justificar. Vigotski (2010) deixa isso claro:

Todo conhecimento sempre surgiu no fim das contas de alguma demanda ou necessidade prática, e se no processo de seu desenvolvimento ele se separa das tarefas práticas que o geraram, nos pontos finais desse desenvolvimento ele torna a voltar-se para a prática e na encontra a sua suprema justificativa, confirmação e verificação (Vigotski, 2010, p. 273).

Dessa forma, a importância deste estudo deverá ser verificada na ação dos psicólogos escolares que atuam no Ensino Superior, refutando ou não as contribuições aqui apresentadas. Ademais, compreendemos que o psicólogo escolar tem importância fundamental para a construção de uma educação de qualidade, que busca a socialização do conhecimento historicamente produzido e que formem pessoas participativas e atuantes na busca pela transformação desse modelo de sociedade.

Evidenciamos que novos estudos precisam ser realizados, aprofundando os temas aqui apresentados, assim como sugerindo outras possibilidades para a atuação do psicólogo escolar no Ensino Superior. O trabalho com gestores, coordenadores de curso e professores precisa ser mais explorado e sistematizado. Outra possibilidade que não foi abordada neste estudo é a atuação por meio da assistência estudantil, algo que foi mencionado nas entrevistas. E por fim, a intervenção nos cursos de licenciatura, atuando com base nos conhecimentos do processo de desenvolvimento e aprendizagem.

Assim, finalizamos este trabalho com a compreensão de que a Psicologia Escolar e Educacional têm muita importância na efetivação de práticas que buscam a emancipação dos indivíduos, rompendo com ações que levam a alienação. Para tanto, é importante que a ciência acompanhe o desenvolvimento social e histórico, produzindo conhecimentos para a construção de uma sociedade justa e que ofereça condições para desenvolvimento das potencialidades humanas iguais para todos.

\section{Referências}

Asbahr, F. S. F. (2005). A pesquisa sobre a atividade pedagógica: contribuições da teoria da atividade. Revista Brasileira de Educação, n. 29. Recuperado: 20 jun. 2014. Disponível: http:// www.scielo.br/pdf/rbedu/n29/n29a09.pdf

Chauí, M. S.(2003). A universidade púbica sob nova perspectiva. Reunião Anual da Associação Nacional de Pós-Graduação e Pesquisa em Educação. Poços de Caldas-MG. Recuperado: 05 nov. 2011. Disponível: www.scielo.br/pdf/rbedu/n24/n24a02.pdf

Cunha, S. M. \& Carrilho, D. M. (2005). O processo de adaptação ao Ensino Superior e o rendimento acadêmico. Psicologia Escolar e Educacional. Campinas, 9(2). Recuperado: 05 nov. 2011. Disponível: http://www.scielo.br/pdf/pee/v9n2/v9n2a04.pdf

Cury, D. G. (2012). A relação entre professor e aluno no Ensino Superior vista por meio da reprovação. Dissertação de mestrado. Programa de Pós-graduação em Psicologia, Universidade Federal de Uberlândia, Uberlândia, MG.

Instituto Brasileiro de Geografia e Estatística [IBGE] (2011). Censo Demográfico de 2011. Brasília: Ministério do Planejamento, Orçamento e Gestão.

Instituto Nacional de Estudos e Pesquisas Educacionais Anísio Teixeira [INEP] (2013a). Censo da Educação Superior 2011: Resumo Técnico. Brasília: Instituto Nacional de Estudos e Pesquisas Educacionais Anísio Teixeira. 
Instituto Nacional de Estudos e Pesquisas Educacionais Anísio Teixeira [INEP] (2013b). Índice de Desenvolvimento da Educação Básica de 2013. Instituto Nacional de Estudos e Pesquisas Educacionais Anísio Teixeira (INEP). Recuperado: 31 jul. 2014. Disponível: http://portal.inep.gov.br/web/portal-ideb

Instituto Nacional de Estudos e Pesquisas Educacionais Anísio Teixeira [INEP] (2014). Censo da Educação Superior 2012: Resumo Técnico. Brasília: Instituto Nacional de Estudos e Pesquisas Educacionais Anísio Teixeira.

Leontiev, A. (2004). O desenvolvimento do psiquismo (2a. ed.). São Paulo: Centauro.

Lobo, M. B. C. M. (2012). Panorama da evasão no Ensino Superior brasileiro: aspectos gerais das causas e soluções. Cadernos ABMES, n. 25. Recuperado: 31 jul. 2014. Disponível: http://www. institutolobo.org.br/imagens/pdf/artigos/art_087.pdf

Marinho-Araújo, C. M. (2009). Psicologia Escolar na Educação Superior: novos cenários de intervenção e pesquisa. Em C. M. Marinho-Araújo (Org.), Psicologia escolar: novos cenários e contextos de pesquisa, prática e formação. Campinas: Alínea.

Marinho-Araújo, C. M \& Bisinoto, C. (2011). Psicologia Escolar na Educação Superior: atuação no Distrito Federal. Psicologia em Estudo, Maringá, 16 (1), 111-122. Recuperado: 08 abr. 2013. Disponível: http://www.scielo.br/pdf/pe/v16n1/a13v16n1.pdf

Mata, L. P. (2005). As continuidades e as descontinuidades da educação superior no Brasil: as reformas do ensino superior no governo militar e no governo neoliberal. Trabalho necessário, $\mathrm{n}$. 3. Recuperado: 10 nov. 2011. Retrieved from http://www.uff.br/ trabalhonecessario

Ministério da Educação (2007). Reuni: Plano de Reestruturação e Expansão das Universidades Federais - Diretrizes Gerais. Ministério da Educação. Recuperado: 10 nov. 2011. Disponível: http://portal.mec.gov.br/sesu/arquivos/pdf/diretrizesreuni.pdf

Moura, F. R. (2015). A atuação do psicólogo escolar no Ensino Superior: configurações, desafios e proposições sobre o fracasso escolar. Dissertação de mestrado, Programa de Pós Graduação em Psicologia: Universidade Estadual de Maringá, Maringá, PR.

Nunes, E. O. (2012). Educação superior no Brasil: estudos, debates, controvérsias. Rio de Janeiro: Garamond.

Patto, M. H. S. (1990). A produção do fracasso escolar: histórias de submissão e rebeldia. São Paulo: T. A. Queiroz.

Prestes, Z. (2010). Quando não é quase a mesma coisa: análise de traduções de Lev Semionovitch Vigotski no Brasil: repercussões no campo educacional. Escolar. Tese de doutorado, Universidade de Brasília, Faculdade de Educação. Programa de Pós-graduação em Educação, Brasília, DF.
Sampaio, S. (2011). A Educação Superior como Espaço Privilegiado para a Orientação Acadêmica. Em R. S. L. Guzzo \& C. M. MarinhoAraújo (Orgs.), Psicologia escolar: identificando e superando barreiras. Campinas: Alínea.

Santos, A. A. A (1997). Psicopedagogia no $3^{\circ}$ grau: Avaliação de um programa de remediação em leitura e estudo. Pro-posições, 1(01), 27-37. Recuperado: 08 abr. 2013. Disponível: http://www. scielo.br/scielo.php?script=sci_nlinks\&ref=000140\&pid=S0102$7972200200030000900027 \&$ lng $=$ en

Saviani, D. (2003). Pedagogia histórico-crítica: primeiras aproximações (8a. ed.). Campinas, SP: Autores Associados.

Saviani, D.(2010). A expansão do ensino superior no Brasil: mudanças e continuidades. Poíesis Pedagógica, 8(2), 4-17. Recuperado: 05 nov. 2011. Disponível: http://www.revistas.ufg.br/index.php/poiesis/ article/view/14035

Serpa, M. N. F. \& Santos, A. A. A. (2001). Atuação no Ensino Superior: um novo campo para o psicólogo escolar. Psicologia Escolar e Educacional, 5 (1). Recuperado: 05 nov. 2011. Disponível: http://www.scielo.br/scielo.php?script=sci_arttext\&pid=S1413$85572001000100004 \&$ Ing=pt\&nrm=iso

Silva Junior, J. R. \& Sguissardo, V. (2012). Formas e razões da expansão da educação superior pública no Brasil. Em D. Mancebo, M. Bittar, \& V. L. J. Chaves (Orgs.), Educação superior: expansão e reformas educativas. Maringá: Eduem.

Silva, S. M. C., Pedro, L. G., Sicari, A. A., Callegari, A. B., Barbosa, B. C. S. \& Montesino, N. R. (2013). O que pode fazer o psicólogo no Ensino Superior? Anais do XI Congresso Nacional de Psicologia Escolar e Educacional. Universidade Federal de Uberlândia. Uberlândia, MG: Universidade Federal de Uberândia. Recuperado: 31 jul. 2014. Disponível: https://abrapee.files.wordpress. com/2013/12/anais-xi-conpe-issn-1981-2566.pdf

Tanamachi, E. R. \& Meira, M. E. M. (2003). A atuação do Psicólogo como expressão do pensamento crítico em Psicologia e Educação. Em M. E. M. Meira \& M. A. M. Antunes (Orgs.), Psicologia escolar: práticas críticas. São Paulo: Casa do Psicólogo.

Tolstij, A. (1989). El hombre y la edad. Moscou: Progresso.

Tomanik, E. A. (2004). O olhar no espelho: "conversas" sobre a pesquisa em Ciências Sociais. (2a ed.) Maringá: Eduem.

Universidade Federal de Santa Catarina [UFSC] (2008). Apresentação da proposta ao Programa de Apoio ao Plano de Reestruturação e Expansão das Universidades Federais. Universidade Federal de Santa Catarina: Ministério da Educação. Recuperado: 10 nov. 2011. Disponível: http://www.reuni.ufsc.br

Universidade Federal de Santa Maria [UFSM] (2007). Programa de Apoio a Planos de Reestruturação e Expansão das Universidades Federais. Universidade Federal de Santa Maria: Ministério da 
Educação. Recuperado: 10 nov. 2011. Disponível: http://sucuri. cpd.ufsm.br/portal2011/_docs/reuni/PROPOSTA_REUNI_UFSM. pdf

Universidade Tecnológica Federal do Paraná [UTFPR] (2007). Plano de Reestruturação e Expansão da UTFPR. UTFPR: Ministério da Educação. Recuperado: 10 nov. 2011. Disponível: http:// www.utfpr.edu.br/reuni/documentos/Plano\%20REUNI\%20da\%20 UTFPR\%20-\%20Aprovado\%20COUNI-MEC.pdf

Vigotski, L. S.(2008). Pensamento e Linguagem (4a. ed.). São Paulo: Martins Fontes.

Vigotski, L. S. (2000). A construção do pensamento e da linguagem. São Paulo: Martins Fontes.

Vigotski, L. S. (2010). Psicologia Pedagógica (3a. ed.). São Paulo: Martins Fontes.
Vygotski, L. S. (1996). Obras escogidas IV. Madrid: Centro de Publicaciones del M.E.C. y Visor Distribuciones.

Vygotsky, L. S. \& Luria, A. R. (1996). Estudos sobre a história do comportamento: símios, homem primitivo e criança. Porto Alegre: Artes Médicas.

Zavadski, K. C. \& Facci, M. G. D. (2012). A atuação do psicólogo escolar no Ensino superior e a formação de professores. Psicologia USP, n. 23, 638-705. Recuperado: 08 abr. 2013. Disponível: http://www.scielo.br/scielo.php?script=sci_arttext\&pid =S0103-65642012000400004

Zavadski, K. C. (2009) A atuação do psicólogo na formação do professor universitário: contribuições da Psicologia históricocultural. Dissertação de mestrado, Programa de Pós Graduação em Psicologia, Universidade Estadual de Maringá, Maringá, PR.

\section{Sobre os autores}

Fabrício Rodrigues de Moura (fabriciormoura@gmail.com)

Psicólogo da UTFPR, Mestre em Psicologia pelo Programa de Pós-Graduação em Psicologia da Universidade Estadual de Maringá.

Marilda Gonçalves Dias Facci (marildafacci@gmail.com)

Professora do Departamento de Psicologia e Programa de Pós-Graduação em Psicologia da Universidade Estadual de Maringá. Doutora em Educação Escolar pela UNESP-Araraquara e Pós-doutora pelo Programa de Pós-Graduação em Psicologia Escolar e do Desenvolvimento humano da USP. 